\title{
Remarks on the Final-over-Final Condition: A View from Chinese Head-Final Structures
}

\author{
Wei-wen Roger Liao \\ Institute of Linguistics, Academia Sinica
}

\begin{abstract}
The paper discusses the universality of the final-over-final condition (FOFC). It has been proposed that sentence-final particles (SFPs) in Chinese may invalidate the universality of FOFC. This paper argues that the challenge from SFPs is inconclusive since the evidence for the head status of SFPs is lacking. On the other hand, the leftward complement of $\mathrm{N}^{0}$ in Chinese (Huang 2016) poses a greater threat to FOFC. However, it is argued that the violation is caused by a languageparticular word order constraint due to Case directionality (Li 1990). Relating the syntactic FOFC violation to the word order constraint in compounds, it is proposed that FOFC may be understood as an instance of the shape conservation principle (Williams 2003), where the language-particular constraint is satisfied at the expense of a minimal violation of the universal condition.
\end{abstract}

\section{Keywords}

final-over-final condition, head-final structure, representation theory, sentencefinal particle, Chinese syntax

Studies in Chinese Linguistics, Volume 38, Number 2, 2017, 93-118 DOI: 10.1515/scl-2017-0005 (C2017 by T.T. Ng Chinese Language Research Centre, Institute of Chinese Studies, The Chinese University of Hong Kong 


\section{Introduction}

The paper reviews the final-over-final condition of admissible word orders, or FOFC (Biberauer et al. 2014; Biberauer and Sheehan 2013, et seq.), which argues that a head-initial phrase (YP) cannot be the complement of a head-final phrase (XP) when $\mathrm{X}$ and $\mathrm{Y}$ share the same categorial feature (i.e., in the spine of an extended projection), as given in (1): ${ }^{1}$

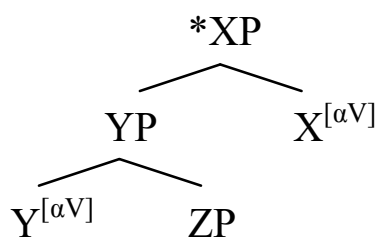

It has been argued that sentence-final particles (SFPs) in Mandarin Chinese pose a threat to the universality of FOFC because SFPs are claimed to be head-final functional heads that take a head-initial complement clause (Erlewine 2017; Lee 1986; Pan 2015; Pan and Paul 2016a, Pan and Paul 2016b; Paul 2014, Paul 2015, among many others). The claim is critically reviewed and eventually dropped because there is no strong empirical motivation for us to adopt the head analysis of SFPs. On the other hand, it is observed that Chinese NPs may provide a more challenging counterexample to FOFC, given that the $\mathrm{N}^{0}$ may take a head-initial complement DP to its left, as argued in Huang (2016), resulting in a FOFC-violating structure. Finally, we argue that FOFC can be compared to the shape conservation principle (Williams 2003), and the violation of FOFC is due to a language-specific constraint, which may override the universal condition as a last resort.

The paper is organized as follows. Section 2 reviews the head-final $\mathrm{C}$ analysis of SFPs, and shows that there is no strong empirical evidence in favor of such an analysis. Even if we adopt a cyclic model of FOFC (Erlewine 2017), evidence is still lacking. Section 3 shows why the nominal complementation in Mandarin Chinese may pose a greater threat to FOFC. Section 4 discusses a similar word order flipping effect in compound formations in English and Chinese and Li's (1990) proposal that Mandarin Chinese is an underlying head-final language. We discuss the theoretical implications of such an analysis with respect to the nature of FOFC.

1 I thank an anonymous reviewer for pointing out to me that FOFC has been renamed and expanded as a condition rather than a constraint (see Sheehan et al. 2017). 


\section{Sentence-final particles: The end of FOFC?}

\subsection{SFPs as head-final Cs}

It has been claimed that SFPs in head-initial languages are counterexamples to FOFC, since SFPs are base-generated in the head-final structure, while the complement is head-initial. Specifically, Pan (2015), Pan and Paul (2016a, 2016b) and Paul $(2014,2015)$ propose that the SFPs in Chinese are base-generated as the head-final $\mathrm{C}^{0}$ in the split CP system (Rizzi 1997). Since Chinese is otherwise head-initial in the verbal extended projection, the structure gives rise to a FOFC violation, as given in (2):

(2) The FOFC-violating structure of SFPs

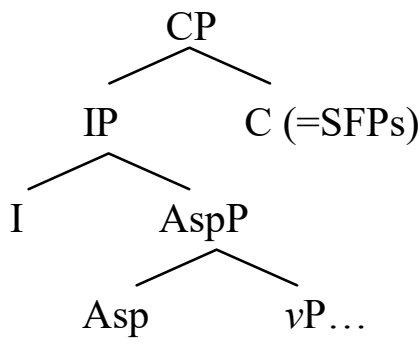

Notice that in order to generate a FOFC-violating structure, SFPs must be a syntactic head that selects the IP complement. However, it is not really clear whether such a condition is met (Chan 2013; Biberauer 2017). The C-head analysis is based on four properties of SFPs. First, multiple occurrences of SFPs display strict ordering, which conforms to the prediction of the left periphery hypothesis (Cinque 1999; Rizzi 1997, Rizzi 2004, et seq.). Second, SFPs select certain types of clauses. Third, they display root properties, and lastly, SFPs take scope over the whole clause (since they occupy the dominating CP periphery). In what follows, these properties are consecutively examined, and it is argued that none of the properties is unique to functional heads; therefore, they are not strong evidence for the functional head analysis of SFPs.

The strict ordering restriction of SFPs refers to the fact that when multiple SFPs are stacked, the structurally higher SFPs should appear in the outer position, as in (3), where the yes/no question particle $m a$ always follows the sentence-final $l e$. The latter expresses the perfect aspect or the "change-of-state" meaning ( $\mathrm{Li}$ and Thompson 1981; Soh 2009):

(3) Zhangsan chi hanbao le ma?

Zhangsan eat hamburger LE Q

'Has Zhangsan eaten the hamburger?'

While it is true that SFPs are subject to the strict ordering restriction, this does not necessarily mean that SFPs are heads. As shown in Cinque (1999), adverbs selected 
by functional heads are also subject to the same strict ordering restriction. At best, the strict ordering phenomenon shows that SFPs are correlated to functional heads, but it is by no means knock-down evidence for the claim that SFPs are functional heads per se.

The second and the third properties of SFPs suffer from the same conceptual problem. They are properties correlated to functional heads, but they do not offer direct evidence for the head status of SFPs. To wit, the adverb shenzhi 'even' in Chinese selects the type of the associated clause (only indicative sentences are compatible with shenzhi) (4), and it displays root phenomena as well (5) (Liao 2016; Liao and Jheng 2015). Nevertheless, we do not take it for granted that shenzhi is a functional head:

(4) a. Zhangsan shenzhi xihuan liulian. [Indicative] Zhangsan even like durian 'Zhangsan even likes durians.'

b. *Shei shenzhi xihuan liulian? [Interrogative] who even like durian

c. *Shenzhi chi liulian ba! [Imperative] even eat durian SFP

(5) a. *Ruguo Zhangsan shenzhi chi liulian, Lisi jiu chi. if Zhangsan even eat durian Lisi then eat Intended: 'If Zhangsan even eats durians, Lisi will, too.' b. *Zhangsan shenzhi chi liulian shi zhen de. Zhangsan even eat durian be true DE Intended: 'That Zhangsan even eats durians is true.'

None of the properties reviewed so far provide conclusive evidence for the C-head status of SFPs. In fact, if we carefully review the scope properties of SFPs, it may turn out that the C-head analysis of SFPs is inadequate. The functional head analysis suggests that SFPs always take scope over the entire clause/CP, including the subject (but see Erlewine 2017 and Tang 2015; we return to the former in Section 2.2). However, it is observed that the subject may escape from the scope of SFP, especially when there is an associated adverb in the sentence. For example, when the SFP le is associated with the adverb yijing 'already' in the sentence, both of them contribute to the perfect aspectual meaning (or the change-of-state [CoS] meaning). The following sentences show that the genuine scope-bearing element is not the SFP le, but the associated adverb yijing. The ambiguous scope phenomenon can still be observed when the adverb is not overt. In those cases, the sentence is disambiguated by relevant contexts:

(6) a. (Yijing) meiyou ren yong daziji le. already no person use type-writer LE 'It has become such that no one is using typewriters.' (perfect/CoS > no) 


\section{b. Meiyou ren (yijing) xie-wan gongke le. no person already write-finish homework LE \\ 'No one is such that he has finished his homework.' (no > perfect/CoS)}

The scope interaction of (6) can be read from the surface structure, where the perfect aspect has out-scoped the negative subject 'no one' in (6a), but the negative subject takes the scope over the perfect aspect in (6b). What is crucial for us here is that the negative subject can scope over the SFP le, contrary to what we might predict from the C-head analysis. ${ }^{2}$ In addition, the meanings of SFPs are often vague and ambiguous. Take the SFP $l e$ as an example again. When it is associated with the adverb yijing 'already' (or a dynamic predicate), it contributes to a perfect aspectual (or $\mathrm{CoS}$ ) meaning. On the other hand, when the SFP le is associated with the degree adverbs like tai 'too' or zui 'most' and the speaker-oriented particle like $j i u$ 'then/already', its meaning may shift. Consider the following cases, where the SFP le is obligatory, but it does not carry the perfect aspect or the CoS meaning:

(7) a. Zhangsan tai gao le.

Zhangsan too tall LE

'Zhangsan is too tall.' (* 'Zhangsan has become too tall.')

b. Zhangsan zui xihuan Lisi le.

Zhangsan most like Lisi LE

'Zhangsan likes Lisi the best.' (* 'Zhangsan has liked Lisi the best.')

c. Yi ge ren jiu gou le.

one CLF person then enough LE

'One person is enough.'

The sentences in (7a-b) refer to states (be tall and like), so the SFP le can hardly be said to have a perfect or a CoS meaning. Instead, the SFP le in these contexts seems to be hinged on the comparative and superlative meanings of too and most. (7c) is the answer to a question like "How many people do you need?", and it is not obvious whether such a sentence involves an aspectual or CoS meaning, either, but the use of $l e$ here is associated with the scalar particle jiu 'then/already' (see Lai 1999). While a precise analysis of SFP le is pending, the observation suggests that le might not be a functional head that typically refers to a more

2 One might argue that meiyou ren 'no one' is an independent clause or a hanging topic, and the le clause is embedded under it. This is implausible, given that a (resumptive) subject pronoun cannot occur in the le clause, and the monotone decreasing no NP or few NP is an unlikely topic (Ko 2005; Tsai 2015):

(i) Meiyou ren (*ta[-men]) yijing $(* \operatorname{ta}[-m e n])$ xie-wan gongke le. neg person he/they already he/they write-finish homework LE 
precise grammatical notion and has a consistent meaning. ${ }^{3}$

Most work on SFPs does not concentrate on their association with modal adverbs. In fact, there is an extensive mutualism between adverbs and SFPs. For example, Tang (2006) and Tang and Cheng (2014) surveyed a wide range of SFPs in Cantonese and found that each SFP in Cantonese can be accompanied by at least one associated adverb (the relevant structure is referred to as the discontinuous structure and is also observed in Mandarin Chinese, which has fewer SFPs than Cantonese):

(8) a. Ngo caa'mdo gong-jyun gamzai.

I almost speak-finish almost

'I almost finished talking.'

b. Gaoging bingo heoi sin?

GAUGING who go SIN

'After all, who will go?'

c. Mtung keoi wui dak zoeng me?

Mtung he will get prize ME

'Don't you think he will get the prize?'

d. Waakze keoi hang zyu faan gwaa.

WAAKZE he willing cook rice GWAA

'Maybe he is willing to cook.'

The strong liaison between particles and sentential adverbs is highly reminiscent of modal particles in languages such as German. ${ }^{4}$ Like most sentential adverbs in English, these modal particles express speaker-oriented meanings, such as attitudes towards the proposition or emphasis; on the other hand, modal particles are highly grammaticalized elements, like SFPs, and their syntactic statuses are aberrant from modal auxiliaries and adverbs that express similar discourse functions (see Abraham 2000; Bayer 2012; Gast 2008; König 1991; Zimmermann 2008, and the references therein). Such phenomena suggest that more work needs to be done in this direction in order to reveal the true nature of SFPs.

\subsection{A phase-based account: Erlewine (2017)}

Erlewine (2017) offers an alternative perspective of looking at the counterexample to FOFC posed by SFPs in Chinese. Erlewine's proposal is that FOFC is cyclically evaluated, and the FOFC domain is equivalent to the spell-out domain. Since

3 A pragmatic theory of the SFP le is proposed in Soh (2009), according to which the particle le involves a negative presupposition, and the speaker either accepts or rejects the negative presupposition, leading to the $\mathrm{CoS}$ meaning or the unexpected reading, respectively. While the account disassociates the particle le from the aspectual meaning, it still seems to fall short of accounting for (7). (7a-b) do not carry negative presuppositions like "Zhangsan is not tall" or "Zhangsan does not like Lisi". (7c) being new information (an answer to a question), the negative presupposition "one person is not enough" is not obviously triggered, either.

4 I thank an anonymous reviewer for pointing this out to me. 
the spell-out domain is defined over phases (Chomsky 2001), it is predicted that violations of FOFC can only be observed in phase edges, namely, in CP and $v \mathrm{P}$ peripheries. The $\mathrm{CP}$ periphery is the typically assumed position for SFPs to occur. On the other hand, to substantiate the idea that $v \mathrm{P}$ also represents a FOFC domain, Erlewine argues that low sentence-final particles, such as le and eryi in Mandarin Chinese, are located in the lower phasal periphery (between TP and $v \mathrm{P}$ ). Therefore, SFPs are tolerated exceptions to the FOFC since they occupy the edges of the spell-out domains.

While Erlewine's proposal is conceptually appealing, evidence for the socalled "low Chinese SFPs" is not as strong, and the phenomena associated with the low SFPs are not without alternative explanations. Let us focus on the SFP le for our present purpose. We shall critically review the evidence provided in Erlewine (2017) for the claim that le is base-generated in the lower phrase edge position.

The first piece of evidence comes from the distinction between $b u$ and $b u$-shi. Following Soh and Gao (2006), Erlewine shows that the presupposition triggered by the SFP le has an LF scope above the verbal negation $b u$, but under the metalinguistic negation bu-shi (see Soh and Gao 2006: 118-119 and Erlewine 2017: 47-48):

(9) a. Ta bu xiang jia le.

he NEG miss home LE

'He does not miss home now, (but he did before).'

(LE $>$ Neg, *Neg $>$ LE)

b. Ta bu-shi xiang jia le.

he NEG miss home LE

'It is not the case that he misses home now, (while he did not miss home before).'

$(*$ LE $>$ Neg, Neg $>$ LE)

Given the contrast, it is argued that the SFP le is base-generated in a structural position between $b u$ (taken as the VP negation) and bushi (taken as the TP negation). While the relative scope between the negation form and the presupposition of $l e$ is correct, it is highly questionable whether the relative scope can be used as evidence in determining the base position of $l e$ in syntax. Notice that the interaction between the presupposition and the (metalinguistic) negation has long been a debated topic in semantics and pragmatics since Horn (1985) (see also Seuren 1988). The received observation is that the verbal negation does not block the presupposition (they are presuppositional holes that let presuppositions pass through at LF), but the metalinguistic negation may cancel the presupposition. This is exactly what we observed in (9) - the verbal negation $b u$ lets the negative presupposition of le go through (and it takes scope over the entire proposition at LF), while the 
metalinguistic negation $b u$-shi may cancel the presupposition. ${ }^{5}$ However, the LF scope properties are not meant to be translated to the base syntactic positions of le and $b u$. Rather, the semantic/pragmatic distinctions between the verbal negation and the metalinguistic negation can be solely responsible for the distinct scope interactions. Therefore, the observed scope interactions cannot be strong syntactic evidence for the low structural position of le.

The second piece of evidence provided by Erlewine (2017) comes from the contrast between the two modals - neng 'can/be able to/be allowed to' and keneng 'may/might'. Following Lin (2011), Erlewine (2017: 50) shows that le takes the scope over the deontic modal neng, but under the epistemic modal keneng:

(10) a. Zhangsan neng qu Taibei le.

Zhangsan can go Taipei LE

'It has become the case that Zhangsan is able/allowed to go to Taipei.'

(LE > can)

b. Zhangsan keneng qu Taibei le.

Zhangsan might go Taipei LE

'It might be the case that Zhangsan has travelled to Taipei.' (might $>$ LE)

However, unlike Lin's bi-clausal analysis, which argues that neng is a modal verb that takes a non-finite clause as the complement (e.g., $\left[_{\mathrm{CP}}\right.$ le ... $\left[_{\mathrm{VP}} n e n g\left[_{\mathrm{CP}}\right.\right.$ PRO qu Taibei]]] 'to go to Taipei'), Erlewine (2017) adopts a mono-clausal analysis of the deontic modal in Chinese and argues that the scope phenomena show that $l e$ is sandwiched in a low structural position between TP and $v \mathrm{P}$ (e.g., $\left[_{\mathrm{TP}} \ldots\right.$ le $\left[_{\mathrm{FP}} n e n g\right.$ [vP qu Taibei]]] ) (see also Grano 2015). Again, the interesting scope properties from Lin (2011) among the epistemic modal, the SFP le, and deontic modal are precise, but the problem is that there is more than one way of interpreting the LF scope phenomena into syntax, and there is no strong evidence against the biclausal analysis in Lin $(2011,2012)$ (see also Lin and Tang 1995 for the proposal that

5 Notice that the negative presupposition ("while he did not miss home before") is not necessarily triggered in (9b), but the entire presupposition can be cancelled given that bu-shi is a metalinguistic negation, such as "because he did not have a home' or "because he is already at home", and the proposition can even be strengthened:

(i) Ta bu-shi chi bao le, ta bao-dao kuai tu le.

he NEG eat full LE he full-to almost throw.up LE

'It is not the case that he is full, but he is so full that he is going to throw up.'

The negative presupposition triggered by le in the first proposition ("he is not full in the immediate past") is not triggered in this case. 
modal auxiliaries are verbs in Chinese). ${ }^{6}$ In fact, some speaker-oriented evaluative adverbs and habitual adverbs may appear under neng 'can', which undermines the monoclausal analysis of the modal verbs in Mandarin Chinese:

(11) a. Zhangsan neng [chang-chang qu Taibei].
Zhangsan can often go Taipei
'Zhangsan is able/allowed to go to Taipei often.'
b. Wo hen gaoxing Zhangsan neng [xingyun-de tao-guo-yi-jie].
I very happy Zhangsan can fortunately escape.the.danger
'I am very happy that Zhagnsan can fortunately survive.'
c. Wo zhi neng [yihan-de, gen ni shuo sheng baoqian].
I only can unfortunately to you say CLF apology
'Unfortunately, I can only apologize to you.'

Arguably, these adverbs are adjoined to the split IP or CP zone according to Cinque's (1999) cartographic theory. It is questionable, then, whether neng really occupies a structural position lower than TP (as assumed in the mono-clausal analysis adopted in Grano 2015, 2017 and Erlewine 2017). Again, the evidence presented in Erlewine (2017) is not strong enough in favor of the low structural position of le.

Another argument adopted by Erlewine (2017) is that the SFP le cannot license the existential reading of the wh-subject (citing examples from Li 1992),

6 According to Lin $(2011,2012)$, the reason why le cannot appear in the embedded clause is that the non-finite $\mathrm{T}$ in the embedded clause is not compatible with the temporal semantics of le. Jonah Lin's account is critically reviewed in Grano (2015, 2017), in which Hacquard's (2006) theory is assumed (that the aspectual phrase dominates the root modal phrase). However, it should be pointed out that unlike Hacquard (2006, 2009), Mandarin does not allow any aspectual markers to occur with the root modal (i), while Hacquard's theory is built upon languages that permit co-occurrence of the root modal and the perfective aspect, such as French (ii), and the theory predicts that the perfective aspect may shift the modal meaning of the root modal (see Bhatt 1999; Hacquard 2009):

(i) *Zhangsan neng chi-le/-guo/-zhe zhe wan fan.

Zhangsan can eat-PFV/-EXP/-PROG this CLF rice

'(lit.) Zhangsan is allowed to have done eating/have eaten/be eating the rice.'

(ii) Jane put traverser le lac à la nage, \#mais elle ne le fit pas.

Jane can-PST-PFV cross the lake by swim, \#but she it do-PST-PFV NEG.

'Jane managed to swim across the lake, \#but she didn't do it.'

An alternative account that may capture Lin's idea is that the ability/deontic modal neng is associated with a generic operator (without reference to a specific situation) (Bhatt 1999; Tsai 2001), but the aspectual semantics of le requires the opposite of that (it requires a specific reference time as an anchor), and le cannot be embedded under the ability/deontic modal due to the semantic conflict. I shall skip the details regarding the bi-clausal and the mono-clausal analyses. Readers who are interested may find detailed discussion in Erlewine (2017), Grano (2015, 2017), Lin (2011), and Lin and Tang (1995). 
which hints that the SFP le does not take scope over the subject: ${ }^{7}$

(12) a. Shei shuo-hua le (?)

who speak LE

(i) 'Who spoke?'

(ii) *'Someone spoke.'

b. Ta shuo shenme le (?)

3sG speak what LE

(i) 'What did he say?'

(ii) 'He said something.'

The contrast, however, can be explained by the fact that existential indefinite subjects are very restricted in Chinese in the first place, and they need to be licensed by you (Li 1998; Tsai 2001), as shown in (13):

*(You) ji ge ren shuo-hua le.
have several CLF person speak
'Several people have spoken.'

If we filter out the factor of you by employing the quantity-denoting subject ( $\mathrm{Li}$ 1998; Tsai 2001) in the scope test (for example, as the answer to the how-many question), le can easily take scope over the indefinite subject:

(14) Q: Duo-shao ren muqian bu-neng lai shang-ke? how.many people so.far not-able come attend-class

'How many people cannot come to class so far?'

$\mathrm{A}: \mathrm{Wu}$ ge ren bu-neng lai le (ganggang cai san ge).

five CLF person not-can come LE previously only three CLF

'It has come to the situation that five people cannot come to class (only three people could not a while ago).'

[LE $>$ five]

Recall the sentences in (6). We also see that the subject mei-you ren 'no one' may take scope either above or under the SFP le. It is therefore not evident to say that the SFP le is base-generated in a lower position than the subject position.

7 Independently, even in the object position, it is much more difficult for shei 'who/someone' to obtain an existential reading without an adverb like haoxiang 'seemingly' or the A-not-A question form. The asymmetry between shei 'who/someone' and shenme 'what/something' is rarely reported in the previous work, yet this can be another reason why the subject shei fails to be interpreted as the existential $w h$-phrase in (12):

(i) Zhangsan da-le shei le (?)

Zhangsan hit-PFV who LE

a. 'Who has Zhangsan hit?'

b. *'Zhangsan has hit someone.'

(ii) Zhangsan haoxiang/shi-bu-shi da-le shei le.

Zhangsan seemingly/be-not-be hit-PFV who LE

a. 'It seems that Zhangsan has hit someone'

b. 'Is it true that Zhangsan has hit someone?' 
All in all, none of the data provided in Erlewine (2017) represent decisive evidence for the claim that low SFPs like le occupy the low phase edge position; therefore, the cyclic model of FOFC (though conceptually appealing) cannot be verified by empirical data, and it might not represent a superior model to the original extended projection model (Biberauer et al. 2014). In the following section, another challenging configuration from the nominal complementation in Chinese is presented. We argue that such a configuration presents a more valid and challenging case to both the phase-based model and the extended projection model of FOFC.

\section{Challenge to FOFC: The complement- $\mathrm{N}^{\mathbf{0}}$ structure in Chinese}

A much more troubling case against FOFC is the leftward nominal complement of $\mathrm{N}^{0}$ in Chinese (or the complement- $\mathrm{N}^{0}$ structure). Unlike the dingyu 'determinative' analysis in the traditional grammar (which treats pre-nominal phrases as a uniform category), Huang (2016) proposes that the complement-adjunct distinction can be maintained in pre-nominal phrases in Chinese. For expository convenience, only a subset of arguments is reproduced here. Readers who are interested in the details of the arguments are referred to Huang (2016), from which most of the examples in this section are cited.

The first piece of evidence comes from event selection, exemplified in (15):
a. [Zhangsan tiaowu] de wuban
Zhangsan dance DE dance-partner
'Zhangsan's dance partner'
b. *[Zhangsan tiaowu] de nühai
Zhangsan dance DE girl
Intended: 'the girl with whom Zhangsan danced'

The contrast shows that if the head noun makes a clear reference to an event (e.g., the compound wu-ban 'dance-partner' may refer to a particular dancing event), then it may select a corresponding eventive clause as its complement; therefore, the head noun wu-ban 'dance-partner' may select the pre-nominal dancing event, but the head noun nühai 'girl' cannot (the latter does not make explicit reference to any event).

Huang (2016) then argues that the so-called "gapless" relative clause (RC) in Mandarin (16) is also subject to the complement analysis; that is, the gapless RC is the complement of the head noun, and they are engaged in event selection (e.g., the sound generated from Zhangsan's piano-playing event and the consequence resulting from Zhangsan's bribery event), and it should not be treated as the typical relative clause, which is a modifier/adjunct:

(16) a. [Zhangsan tan gangqin] de shengyin

Zhangsan play piano DE sound

'the sound of Zhangsan's playing piano' 
b. [Zhangsan tanwu] de houguo

Zhangsan bribery DE consequence

'the consequence of Zhangsan's bribery'

On the other hand, gapped relative clauses, which are adjuncts, are not subject to event selection, and any noun head is permitted, as shown in (17). Observe the contrast between (15b) and (17b):

(17) a. $\left[e_{i}\right.$ gen Zhangsan tiaowu] de wuban $n_{i}$ with Zhangsan dance DE dance-partner 'the partner who danced with Zhangsan'

b. $\left[e_{i}\right.$ gen Zhangsan tiaowu $]$ de nühai ${ }_{i}$ with Zhangsan dance DE girl 'the girl who danced with Zhangsan'

The proposal can also be supported by the relative word order between complements and adjuncts. We predict that a complement is always closer to the head than adjuncts are. As shown in Huang (2016), the prediction is borne out. The nominal complement in (18a) is closer to the head noun than the gapped relative clause, but the reverse word order gives rise to ungrammaticality (18b):

$$
\begin{aligned}
& \begin{array}{lll}
\text { a }_{\mathrm{RC}} \text { Women } & \text { zhengzai kaolü de } \\
1 \mathrm{PL} & \text { currently } & \text { consider DE }
\end{array}\left[\begin{array}{l}
\text { Compl } \\
\text { yao-bu-yao kuoda } \\
\text { yes-no expand }
\end{array}\right. \\
& \text { zhaosheng] de wenti } \\
& \text { recruitment DE question } \\
& \text { 'the question whether to increase student enrollment that we are } \\
& \text { b. * }{ }_{\text {Compl }} \begin{array}{llll}
\text { Yao-bu-yao kuoda } & \text { zhaosheng } & \text { de }] \\
\text { yes-no } & \text { expand } & \text { recruitment } & \text { DE }
\end{array} \\
& { }_{R C} \text { women zhengzai kaolü de] wenti } \\
& \text { 1PL currently consider DE question }
\end{aligned}
$$

Coordination provides yet another piece of evidence. As is well known, adjuncts and complements cannot be coordinated, and as predicted, the nominal complement and the adjunct cannot be coordinated:

(19) a. ${ }^{*}\left[_{\text {Compl }}\right.$ Zhangsan tan gangqin de $]$ he $\left[_{\mathrm{RC}}\right.$ Lisi fachu $e$ de $]$ shengyin Zhangsan play piano DE and Lisi produce DE sound Intended: 'the sound of Zhangsan's playing piano and the sound that Lisi produced'

b. *na ge $\left[_{\mathrm{RC}}\right.$ women zhengzai kaolü $e$ de $]$ he DEM CLF 1PL currently consider DE and

[Compl yao-bu-yao kuoda zhaosheng] de wenti yes-no expand recruitment $\mathrm{DE}$ question

Intended: 'the question whether to expand the enrollment that we are considering' 
There are several other pieces of evidence in Huang (2016), but for our purpose here, the evidence is already strong enough to show that $\mathrm{N}^{0}$ is able to take a complement to its left. Now a problem arises when the $\mathrm{N}$ head takes another DP as its complement. Such a configuration results in a FOFC violation because the $\mathrm{N}^{0}$ is head-final, while the complement is head-initial, as illustrated below (the syntactic position of $d e$ is pending here): ${ }^{8}$

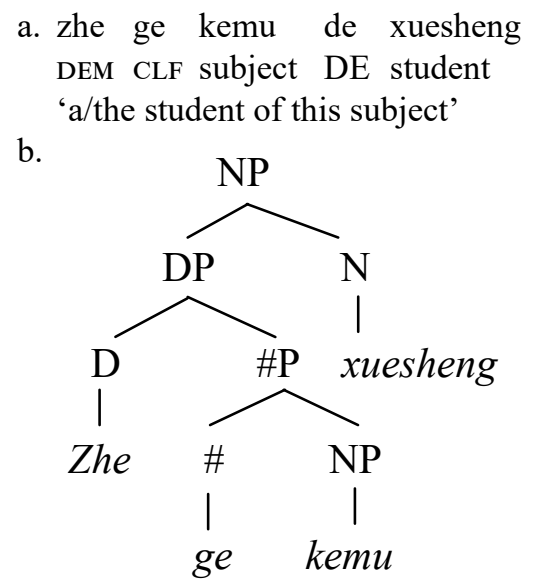

The problem is eminent since in the parallel verbal domain, where the head verb takes a CP complement, it is claimed that none of the known languages displays the FOFC-violating configuration in (21) (Biberauer et al. 2014):

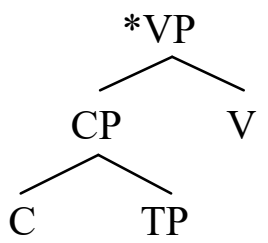

8 One possible way to neutralize the FOFC violation is to assume that the numeral-classifier and determiner are not functional extended projections of nouns, but modifiers of the head noun. While the approach may be adopted as an ad hoc rescue strategy, the theoretical cost seems too much, as there is a sharp contrast between the modifier and the non-modifier numeral-classifier phrases (Li 2013; Tang 2005), as in (i), where the non-modifier numeral-classifier phrase (with an optional de) has a monotonic (pseudo-partitive) reading (ia), the modifier numeral-classifier phrase (with an obligatory de) has an attributive reading (ib) (Schwarzschild 2006). We therefore follow Tang (1990) and Li (1999), among many others, in assuming that the numeral-classifiers in question are functional extended projections of the noun:

(i) Yi gongjin de yanlei

one kilogram DE tear-drop

a. 'one kilogram of teardrop'

[pseudo-partitive]

b. 'a teardrop that weighs one kilogram' [attributive] 
Meanwhile, if the complement is a nominal DP, an apparent FOFC-violation can be found:

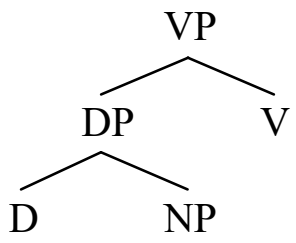

To solve the CP-DP asymmetry, Biberauer et al. (2014) adopt the notion of categorial identity of the extended projection, according to which the "spine" projection of a category is extended as long as it is embedded in a head that has the identical categorial feature, and the domain of FOFC is restricted to a single extended projection (or the spine). Therefore, in (21), since CP has a [+V] categorial feature, which is identical to the head verb, the whole configuration is considered a single extended projection, and therefore, FOFC is violated if the head-final VP and head-initial CP are in the same spine. On the other hand, (22) is immune from the FOFC violation because the DP complement belongs to another extended projection of the categorial specification $[-\mathrm{V}]$, which is distinct from the head verb. The configuration therefore conforms to FOFC. This being said, the nominal complement of Chinese has the same categorial specification as the head noun in $(20 \mathrm{~b})$, both of which are [-V]. Incorporating the notion of extended projection therefore does not get rid of the problem caused by the Chinese complement- $\mathrm{N}^{0}$ structure.

A second approach that may avoid the problem is to claim that de is a functional head that mediates the head-complement relation, such as in (23) (see Paul 2015; Zhang 1999, Zhang 2012, among others). The structure does not cause a FOFC violation because it is a uniform head-initial construction. Let us assume that de heads a deP (or any FP for that purpose), whose specifier is occupied by the alleged complement DP phrase:

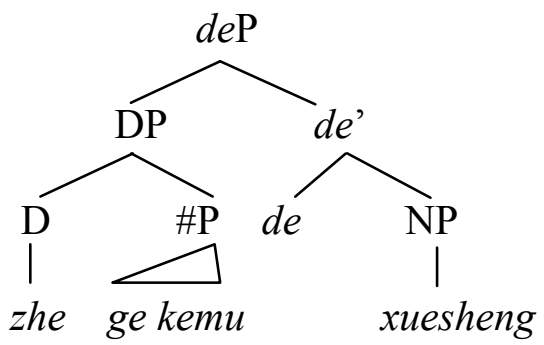

The analysis, however, faces an empirical problem from the NP-ellipsis sentences. Li (2012) and Huang (2016) note that de can license NP-ellipsis only if the preceding element is a modifier/adjunct (24a), and if the preceding element is a complement, as in (24b-d), NP-ellipsis is not allowed: 
(24) a. $\left[_{\mathrm{RC}} e_{\mathrm{i}}\right.$ lai canjia bisai de] $\left(\right.$ ren $\left._{\mathrm{i}}\right)$

come participate game DE person

'people who came to participate in the race'

b. $\left[_{\text {Compl }} \begin{array}{lll}\text { ta tiaowu de }] & * \text { (wuban) } \\ 3 \text { SG dance DE dance-partner }\end{array}\right.$

'the partner whom he danced with'

c. [Ta chang-ge de] shengyin bi [ni tan qin de]*(shengyin) haoting 3sGsing DE voice than you play piano DE sound better

'The voice of her singing is better than the sound of your playing piano.'

d. Wuli de xuesheng da-le na ge huaxue de *(xuesheng) physics DE student hit-PFV DEM CLF chemistry DE student

'The student of physics hit the student of chemistry.'

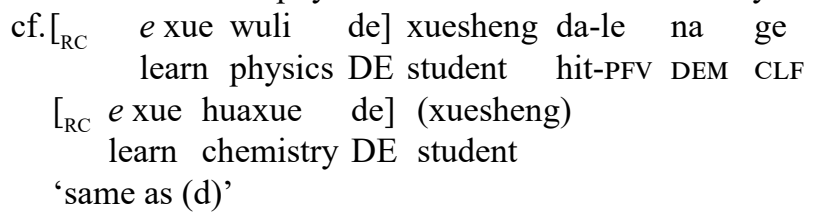

The functional head analysis of $d e$, however, fails to predict the complement/ adjunct asymmetry. Furthermore, it leads to a wrong prediction that $(24 b-d)$ were grammatical since the functional head should be able to license the elided NP (Li 2013; Tang 2005). Therefore, if we try to analyze away the problem by stipulating the functional head analysis of $d e$, we face a danger of losing the decent account for the adjunct/complement asymmetry in Huang (2016).

\section{Conservation principle and FOFC}

In this section, we would like to provide a speculative account for the FOFC violation found in Chinese, and make predictions of where we might find FOFC violations. In order to do so, we need to look beyond syntax and examine similar ordering rules in other grammatical components. In this respect, the representational theory in Williams (2003) is adopted. It is proposed that the universality of FOFC follows from the more general conservation principle that regulates mapping among various grammatical modules, and such a principle can be violated (but only minimally) by language particular surface constraints. In the case of the complement- $\mathrm{N}^{0}$ structure in Chinese, Li's (1990) account is assumed that a complement phrase is merged to the left in the underlying configuration, and only surfaces to the right when it is assigned the structural Case by the $\mathrm{V}^{\mathrm{o}}$ / $\mathrm{P}^{0}$. The inability of the $\mathrm{N}^{0}$ to assign a structural Case and the non-existence of a preposition like English of in Mandarin Chinese therefore create a FOFC-violating configuration (and the CP/DP asymmetry in Chinese). The language-particular Case constraint thus prefers the complement- $\mathrm{N}^{0}$ order to the $\mathrm{N}^{0}$-complement one because the former preserves the underlying word order (head-final) in Chinese when no Case assignment is needed. 
Let us illustrate the idea with the syntax-morphology mapping of English compounds in Williams (2003). The syntactic structure in (25a) can be mapped to a compound in $(25 b[i])$, but not in $(25 b[i i])$ or $(25 b[i i i])$. In the latter two cases, the linear order among supply, gun and army is (in part) isomorphic to the syntax:
a. Syntax: [vP supply [gun [to an army]]]
b. Compound: (i)
[N army [gun [suppli-er]]]
(ii) $*[\mathrm{~N}$ supply [gun [army] -er]]
(iii) $*[\mathrm{~N}$ gun [army [suppli-er $]]]$

On the other hand, in the legitimate compound form (25b[i]), the mirror mapping between syntax and morphology is observed, where the linear order in the syntax is mapped to a reverse order (the mirror image) to best preserve the original mapping from the linear relation to the hierarchical order (if $\mathrm{X}$ is adjacency to $\mathrm{Y}$, then $\mathrm{X}$ immediately dominates $\mathrm{Y}$ ), as in (26):

(26) a. Syntax: supply $>$ theme $>$ goal $=$ [supply [theme [goal]]]
b. Compound:
(i) $\quad[$ [ $[$ goal $]<$ theme $]<$ supply-er $]$
(ii) $*$ [supply $>$ [theme $>$ [goal] $]$-er $]$
(iii) $*[$ [theme $]<$ goal $]<$ supply-er $]$

Given that -er is a suffix that must be attached to a verbal root, the ungrammaticality of (25b[ii]) can be accounted for by the morphological affixation rule, where the suffix requires a verb root to appear in the word-final position. The question then is what blocks the compound in (25b[iii]). Williams (2003) argues that the compound order in $(25 \mathrm{~b}[\mathrm{i}])$, or the mirror mapping, wins out due to the shape conservation principle, where the relations among the internal arguments, is maximally preserved between syntax and morphology even though the linear order is reversed due to the requirement of the suffix $-e r:^{9}$

(27) Shape Conservation Principle

Maximize the identity of relations (precedence, dominance, adjacency, etc.) among corresponding representation levels.

Once the verb is attracted by the suffix to the word-final position, the precedence relations cannot be maintained between syntax and morphology, but the shape conservation principle requires that the structure be flipped (undergoes a symmetric mirror transformation) in order to maximally preserve the hierarchical order and adjacency among the verb and its internal arguments (that is, in a reversed linear order). In this way, we can maximally preserve the original relations (X dominates $\mathrm{Y}$ if and only if $\mathrm{X}$ is adjacent to $\mathrm{Y})$. However, this is not the case in (25b[iii]). The

9 This is fully expected during any symmetry-breaking process, where the underlying symmetry of a system will be maximally preserved through symmetric transformations. For example, the original structure undergoes mirror transformation since the original structure and its mirror image belong to the same symmetry group, in which the identical hierarchical and adjacent orders are preserved (see Liao 2011, Liao 2014a). 
reason is that the linear structure is translated to a different hierarchical order from the original one ( $26 \mathrm{~b}$ [iii]), where supply dominates the goal, which in turn dominates the theme. ${ }^{10}$ Thus, the structure is not optimal because it involves an unnecessary loss of the original relations.

The condition is reminiscent of FOFC in the following sense - the definition of FOFC in Biberauer et al. (2014: 210) involves a spreading rule of the movement diacritics $^{\wedge}$, which says that once a head $x$ in an extended projection is associated with the movement diacritics, then the heads in the same spine c-selected by $x$ are also involved with the movement diacritics. Essentially, the rule generates roll-up movements (or the "flipping effect") up to the $x \mathrm{P}$, resulting in a uniform headfinal structure. We may compare the suffix -er to the movement diacritics. The insertion of -er in (26b) attracts the head-initial verb (which is the most dominating element in the underlying structure) to the head-final position and triggers the chain reaction of flipping the head-initial structure into a uniform head-final structure.

In Chinese, however, two types of compound orders can be found, and one type of compound superficially violates FOFC (the violation is apparent since FOFC was not meant to be a condition on the morphological module in Biberauer et al. 2014, but see Myler 2009 and Roberts 2017). Consider the compounds in (28) and (29): ${ }^{11}$
a. [[xi-yi]
ji]
wash-clothes machine
'washing machine'

10 An anonymous reviewer asks whether the double object construction (verb $>$ goal $>$ theme) would predict another word order between goal and theme in compounds. From the asymmetry of idiom formation, Bruening (2010) convincingly argues that the verb selects two arguments only in the dative frame, and the double object frame involves an additional applicative head above VP in syntax. Arguably, only the verb and its internal argument(s) are involved in the compound formation, and therefore, the double object frame is irrelevant to the compound formation; hence, no compounds with the word order, theme-goal-V-er.

11 An anonymous reviewer points out that (29) does not incur a violation of FOFC because the headfinal $\mathrm{N}^{0}$ and the head-initial $\mathrm{V}^{0}$ do not share the same lexical specification (one is nominal and the other verbal). However, it is not entirely clear how the question should be approached here. First, if FOFC is defined over c-selection and extended projections (Biberauer et al. 2014), it is not clear whether morphological compounds are subject to the same notions. Second, Chinese has a verbal root -zhong 中 (lit. 'in the middle of' or 'attain') that gives rise to a verbal compound (it is not productively used in syntax like other aspectual suffixes), and it is subject to the same distribution as the nominal root -ji 'machine':
(i) a. $\left[_{V}\left[{ }_{V} \mathrm{xi}_{\mathrm{V}}-\mathrm{yi}{ }_{\mathrm{N}}\right]\right.$-zhong $]$ wash-clothes-ZHONG 'doing laundry'
b. $\left[{ }_{\mathrm{V}}\left[{ }_{\mathrm{V}}\right.\right.$ shiwu $_{\mathrm{N}}-$-chuli $\left._{\mathrm{V}}\right]-$ zhong $]$ food-process-ZHONG 'processing food' 
b.

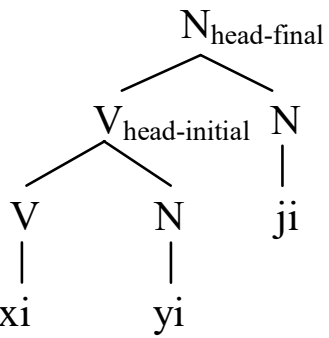

(29) a. [[shiwu-chuli] ji]

food-process machine

'food processor'

b.

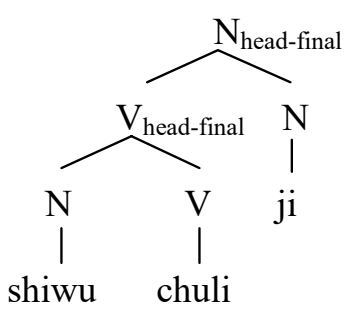

The structure in (28b) superficially violates FOFC, and at the same time, it violates the shape conservation principle found in English compounds. On the other hand, the shape conservation principle (and FOFC) is observed in (29b), in the sense that a word-final verb triggers a reverse bracketing order of its embedded structure. Larger compounds show the same mirror transformation: $:^{12}$

(30) a. xuexiao wucan gongying-zhe (cf. *wucan xuexiao gongying-zhe) school lunch provide-er

'school lunch provider' (= the companies/people that provide lunch to schools)

b.

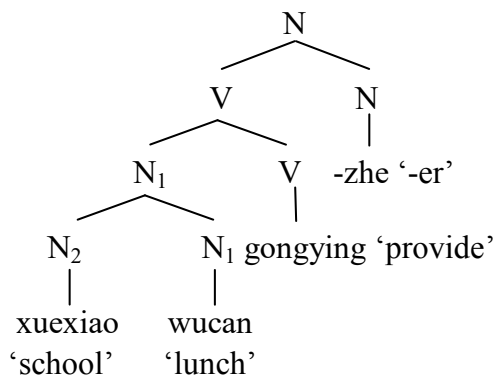

12 The morpheme -zhe 者 means 'person' in Archaic Chinese, but is best analyzed as an affix in modern Chinese (like -er or -ist in English) since it is a bound morpheme and always occurs in the suffix position (see Packard 2000 and Liao 2014b for discussion). 
The question that interests us here is that why the two opposite patterns can be found in Chinese. Careful inspection of (28) and (29) reveals that the compound orders in Chinese compounds are not only subject to the universal condition, but are also subject to a language particular constraint in terms of the syllable structure (Feng 1998, Feng 2002; Starosta et al. 1998). That is, when the verb is monosyllabic in V-N compounds, the monosyllabic root is not a morphological unit that can be suffixed, and therefore, the $\mathrm{N}$ stays in the canonical object position to form a disyllabic compound with the verb, which is then admissible to the syllable requirement of the suffixation. When the verb in the V-N compound is disyllabic or more, on the other hand, it can be suffixed by $-z h e$, and the internal arguments undergo mirror transformation as a last resort in order to conserve the underlying dominance and adjacency relations.

What we learn from the contrast above is that the shape conservation principle (albeit being universal) can be violated if it comes to a conflict with a languageparticular constraint; however, the violation is "minimal" because other relations are maximally preserved (by means of symmetric transformation). Specifically, the language-particular disyllabic constraint in Mandarin compounds overrides the shape conservation principle in the syntax-morphology mapping. In the context of FOFC, we would expect that violations against FOFC can be found due to some other language-particular constraints. ${ }^{13}$ We propose that the FOFC-violating Chinese complement-NP structure also results from a conflict between a universal condition and a language-particular constraint, the latter being Case-related.

Observing that only NPs, but not PPs, may occur in post-verbal positions, Li (1990: 11) argues that Chinese is subject to the language-particular Word Order Constraint: ${ }^{14}$

\section{(31) The Chinese Word Order Constraint}

a. Chinese is head-final except under the requirement of Case assignment.

b. Case is assigned to the right in Chinese.

c. A Case assigner assigns at most one Case.

13 In this respect, the proposed account might be different from the Optimality Theory (OT) (Prince and Smolensky 2004), where all OT-constraints are considered universal, and language variation is due to language-particular rankings. In the proposed system, language-specific constraints (which need to be learned) should exist along with the universal constraints (which are given by UG), and the former are predicted to override the universal constraints. Furthermore, the competition of constraints is restricted to mappings among representation levels (grammatical modules), but does not replace derivations. I leave the empirical consequences of the account pending for future research.

14 Li's directionality constraint is restricted to structural Cases. As for inherent Cases, they are independently regulated by thematic relations and are therefore immune from the constraint ( $\mathrm{Li}$ 1990: 71). In the head-final complement- $\mathrm{N}^{0}$ structure, since the NP complement of $\mathrm{N}^{0}$ receives the inherent oblique Case, it is not subject to the left-to-right directionality constraint and stays in the left of the head N. On independent grounds, Takano (1996) and Fukui and Takano (1998) also argue that the universal order between verb and object is OV rather than VO (contra Kayne 1994), but see Takita (2009). 
The Case-driven word order constraint correctly predicts the asymmetry between the verbal and the nominal head-complement structures. According to Li's Chinese word order constraint, the complement of $\mathrm{V}^{0}$, but not the complement of $\mathrm{N}^{0}$, may give rise to the head-initial structure in Mandarin. Notice that being an underlying head-final language, Mandarin does not have a structure comparable to the of-PP in English, such as the student [of physics] or the destruction [of the city], where the nominal complements physics and the city are assigned Case by the preposition of, resulting in a FOFC-compliant configuration..$^{15}$ Therefore, the language-particular constraint is observed at the expense of the FOFC violation. The asymmetry between the verbal and nominal categories is therefore reduced to (the language-particular) Case directionality.

On the other hand, in prototypical head-final languages like Japanese, there is no such verbal-nominal asymmetry. One possible explanation for the lack thereof also lies in the Case module. If we adopt the analysis in Takano (1996) and Fukui and Takano (1998), the word order constraint of the Chinese type does not need to apply in Japanese because the overt Case-marking system in Japanese allows the Case to be checked without resorting to the head-initial directionality. Given the liberty of Case directionality, we expect that FOFC is maximally respected in Japanese. The result is a uniform head-final configuration across verbal and nominal domains. Therefore, Chinese is particular in this respect because it shows mixed properties of head-initial and head-final languages. Like Japanese, Chinese is an underlying head-final language (for lexical categories), but unlike Japanese, it does not have an overt Case-marking system, and therefore, Chinese must resort to the head-initial directionality to assign the structural Case, resulting in the CP/DP asymmetry in terms of the FOFC violation.

In summary, the reason why Chinese violates FOFC in the leftward complement structure of $\mathrm{N}^{0}$ does not endanger the validity or universality of FOFC, if we view FOFC as a universal condition akin to the shape conservation principle. The universal condition is maximally observed, yet (minimal) violation is allowed if another language-specific constraint intervenes. In the latter case, we expect that the original relations that are not directly affected by the language specific constraint should be maximally preserved through symmetric transformation (e.g., in mirror image or in isomorphism). A representative case is found in Chinese compounds, which illustrate the compliance strategy in face of the conflict between the language-specific constraint and the universal condition.

15 In nominalized verbs, the complement PP, whose head may assign Case to the NP argument, also stays in the underlying leftward position of the nominalized verb in Mandarin:

(i) [dui chengshi de] pohuai

to city DE destruction

'destruction of the city' 


\section{Conclusion}

This paper critically reviews counterexamples to FOFC in Chinese. SFPs in Chinese, which are often claimed to invalidate FOFC, turn out to be too controversial in syntax so that it poses no real threat to FOFC. On the other hand, the head-final complement- $\mathrm{N}^{0}$ structure (Huang 2016) may represent a greater challenge to FOFC. It is suggested that FOFC be derived from a more general shape conservation principle in the sense of Williams (2003), and language-particular constraints from different modules of grammar, such as morphology, phonology, or the Case/ theta module may outrank the more general principle. When there is a conflict, the language-specific constraint supersedes the universal condition, at the expense of a minimal violation of the universal condition; nevertheless, the shape conservation principle predicts that the structure should undergo symmetric transformation to maximally preserve the original ordering. It is therefore suggested that the FOFC violation found in Chinese does not invalidate the universality of FOFC, but it may shed light on understanding typological universals found in language, and how and where exceptions to universal conditions can be found.

\section{Acknowledgments}

The present paper is an expansion of the talk I gave in the Workshop on Word Order of Heads at The Chinese University of Hong Kong. I would like to thank the organizer of the workshop, Sze-Wing Tang, and the participants there, especially Ian Roberts, Thomas Lee, Lawrence Cheung, Niina Zhang, and Mitcho Erlewine. The paper has benefited much from discussions with James Huang, Chih-hsiang Shu, Iris Wang, Sam Jheng, and Grant Kao. I would also like to thank the three anonymous reviewers of $S C L$ for their constructive comments and suggestions. All flaws or errors are mine alone.

\section{References}

Abraham, Werner. 2000. Modal particles in German: Word classification and legacy beyond grammaticalization. In Peter M. Vogel and Bernard Comrie (eds.), Approaches to the typology of word classes, 321-350. Berlin: De Gruyter.

Bayer, Josef. 2012. From modal particle to interrogative marker. A study of German denn. In Laura Brugé, Anna Cardinaletti, Giuliana Giusti, Nicola Munaro, and Cecilia Poletto (eds.), Functional heads (The Cartography of Syntactic Structures, Volume 7), 13-36. Oxford: Oxford University Press.

Bhatt, Rajesh. 1999. Covert modality in non-finite contexts. Philadelphia, PA: University of Pennsylvania dissertation.

Biberauer, Theresa. 2017. FOFC and particles. In Michelle Sheehan, Theresa Biberauer, Ian Roberts, and Anders Holmberg (eds.), The final-over-final condition: A syntactic universal. Cambridge, MA: MIT Press.

Biberauer, Theresa, Anders Holmberg, and Ian Roberts. 2014. A syntactic universal and its consequences. Linguistic Inquiry 45. 169-225.

Biberauer, Theresa, and Michelle Sheehan (eds). 2013. Theoretical approaches to 
disharmonic word order. Oxford: Oxford University Press.

Bruening, Benjamin. 2010. Ditransitive asymmetries and a theory of idiom formation. Linguistic Inquiry 41. 519-562.

Chan, Hok-Shing Brian. 2013. Sentence-final particles, complementizers, antisymmetry, and the final-over-final constraint. In Theresa Biberauer and Michelle Sheehan (eds.), Theoretical approaches to disharmonic word order, 445-468. Oxford: Oxford University Press.

Chomsky, Noam. 2001. Derivation by phase. In Michael Kenstowicz (ed.), Ken Hale: A life in language, 1-52. Cambridge, MA: MIT Press.

Cinque, Guglielmo. 1999. Adverbs and functional heads: A cross-linguistic perspective. New York: Oxford University Press.

Erlewine, Michael Yoshitaka. 2017. Low sentence-final particles in Mandarin Chinese and the final-over-final constraint. Journal of East Asian Linguistics 26. 37-75.

Feng, Shengli. 1998. Prosodic structure and compound words in classical Chinese. In Jerome Packard (ed.), New approaches to Chinese word formation, 197-260. Berlin: Mouton de Gruyter.

Feng, Shengli. 2002. Prosodic syntax and morphology in Chinese. München: Lincom Europa.

Fukui, Naoki, and Yuji Takano. 1998. Symmetry in syntax: Merge and demerge. Journal of East Asian Linguistics 7. 27-86.

Gast, Volker. 2008. Modal particles and context updating - the functions of German ja, doch, wohl, and etwa. In Ole Letnes, Eva Maagerø, and Heinz Vater (eds.), Modalität und Grammatikalisierung, 153-177. Trier: Wissenschaftlicher Verlag. Grano, Thomas. 2015. Control and restructuring. Oxford: Oxford University Press. Grano, Thomas. 2017. Finiteness contrasts without tense? A view from Mandarin Chinese. Journal of East Asian Linguistics 26. 259-299.

Hacquard, Valentine. 2006. Aspects of modality. Cambridge, MA: MIT dissertation.

Hacquard, Valentine. 2009. On the interaction of aspect and modal auxiliaries. Linguistics and Philosophy 32. 279-315.

Horn, Larry. 1985. Metalinguistic negation and pragmatic ambiguity. Language 61. 121-174.

Huang, C.-T. James. 2016. The syntax and semantics of prenominals: Construction or composition? Language and Linguistics 17. 431-475.

Kayne, Richard. 1994. The antisymmetry of syntax. Cambridge, MA: MIT Press.

Ko, Heejeong. 2005. Syntax of why-in-situ: Merge into [Spec, CP] in the overt syntax. Natural Language \& Linguistic Theory 23. 867-916.

König, Ekkehard. 1991. The meaning of focus particles: A comparative perspective. London: Routledge.

Lai, Huei-ling. 1999. Rejected expectations: The scalar particles cai and jiu in Mandarin Chinese. Linguistics 37. 625-661.

Lee, Thomas Hun-tak. 1986. Studies on quantification in Chinese. Los Angeles, CA: University of California, Los Angeles dissertation.

Li, Charles, and Sandra Thompson. 1981. Mandarin Chinese: A functional reference grammar. Berkeley: University of California Press. 
Li, Yen-hui Audrey. 1990. Order and constituency in Mandarin Chinese. Dordrecht: Kluwer.

Li, Yen-hui Audrey. 1992. Indefinite Wh in Mandarin Chinese. Journal of East Asian Linguistics 1. 125-156.

Li, Yen-hui Audrey. 1998. Argument determiner phrases and number phrases. Linguistic Inquiry 29. 693-702.

Li, Yen-hui Audrey. 1999. Plurality in a classifier language. Journal of East Asian Linguistics 8. 75-99.

Li, Yen-hui Audrey. 2012. Mandarin de $\leftrightarrow$ Taiwanese e. Studies in Chinese Linguistics 33. 17-40.

Li, Yen-hui Audrey. 2013. P-insertion and ellipsis. Studies in Chinese Linguistics 34. 99-128.

Liao, Wei-wen Roger. 2011. The symmetry of syntactic relations. Los Angeles, CA: University of Southern California dissertation.

Liao, Wei-wen Roger. 2014a. On the loss of identity and emergence of order: Symmetry breaking in linguistic theory. In Kuniya Nasukawa, and Henk van Riemsdijk (eds.), Identity relations in grammar, 289-320. Berlin: Walter de Gruyter.

Liao, Wei-wen Roger. 2014b. Morphology. In C.-T. James Huang, Y.-H. Audrey Li, and Andrew Simpson (eds.) The handbook of Chinese linguistics, 3-25. Malden, MA: Wiley-Blackwell.

Liao, Wei-wen Roger. 2016. The up and down of even. Paper presented at Theoretical Linguistics at Keio (TaLK-2016). Keio University, 7-9 August.

Liao, Wei-wen Roger, and Wei-cheng Sam Jheng. 2015. How do we get even? Paper presented at the $10^{\text {th }}$ International Workshop on Theoretical East Asian Linguistics (TEAL-10). Tokyo University of Foreign Studies, 13-14 June.

Lin, Jowang, and C.-C. Jane Tang. 1995. Modals as verbs in Chinese: A GB perspective. The Bulletin of Institute of History and Philology 66. 53-104.

Lin, Tzong-hong Jonah. 2011. Finiteness of clauses and raising of arguments in Mandarin Chinese. Syntax 14. 151-186.

Lin, Tzong-hong Jonah. 2012. Multiple-modal constructions in Mandarin Chinese and their finiteness properties. Journal of Linguistics 48. 151-186.

Myler, Neil. 2009. Form, function, and explanation at the syntax/morphology interface: Agreement, agglutination and post-syntactic operations. Cambridge: University of Cambridge M. Phil. Dissertation.

Packard, Jerome. 2000. The morphology of Chinese: A linguistic and cognitive approach. Cambridge: Cambridge University Press.

Pan, Victor Junnan. 2015. Mandarin peripheral construals at syntax-discourse interface. The Linguistic Review 32. 819-868.

Pan, Victor Junnan, and Waltraud Paul. 2016a. Why Chinese SFPs are neither optional nor disjunctors. Lingua 170. 23-34.

Pan, Victor Junnan, and Waltraud Paul. 2016b. What you see is what you get: Chinese sentence-final particles as head-final complements. In Josef Bayer, and Volker Struckmeier (eds.), Discourse particles: Formal approaches to their syntax and semantics, 49-77. Berlin: Mouton de Gruyter. 
Paul, Waltraud. 2014. Why particles are not particular: Sentence-final particles in Chinese as heads of a split CP. Studia Linguistica 68. 77-115.

Paul, Waltraud. 2015. New perspectives on Chinese syntax. Berlin: Walter de Gruyter. Prince, Alan, and Paul Smolensky. 2004. Optimality theory: Constraint interaction in generative grammar. Malden, MA: Blackwell Pub.

Rizzi, Luigi. 1997. The fine structure of the left periphery. In Liliane Haegeman (ed.) Elements of grammar, 281-337. Dordrecht: Kluwer.

Rizzi, Luigi. 2004. The structure of CP and IP. New York, NY: Oxford University Press.

Roberts, Ian. 2017. FOFC and moprhology. In Michelle Sheehan, Theresa Biberauer, Ian Roberts, and Anders Holmberg (eds.), The final-over-final condition: A syntactic universal. Cambridge, MA: MIT Press.

Schwarzschild, Roger. 2006. The role of dimensions in the syntax of noun phrases. Syntax 9. 67-110.

Seuren, Pieter A. M. 1988. Presupposition and negation. Journal of Semantics 6. 175226.

Sheehan, Michelle, Theresa Biberauer, Ian Roberts, and Anders Holmberg (eds.) 2017. The final-over-final condition: A syntactic universal. Cambridge, MA: MIT Press.

Soh, Hooi Ling. 2009. Speaker presupposition and Mandarin Chinese sentence-final le: A unified analysis of the "change of state" and the "contrary to expectation" reading. Natural Language \& Linguistic Theory 27. 623-657.

Soh, Hooi Ling, and Meijia Gao. 2006. Perfective aspect and transition in Mandarin Chinese: An analysis of double -le sentences. In Pascal Denis, Eric McCready, Alexis Palmer, and Brian Reese (eds.), Proceedings of the 2004 Texas Linguistics Society conference, 107-122. Somerville, MA: Cascadilla Proceedings Project.

Starosta, Stanley, Koenraad Kuiper, Siew-ai Ng, and Zhi-qian Wu. 1998. On defining the Chinese compound word: Headedness in Chinese compounding and Chinese VR compounds. In Jerome Packard (ed.), New approaches to Chinese word formation: Morphology, phonology and the lexicon in modern and ancient Chinese, 347-370. Berlin: Mouton de Gruyter.

Takano, Yuji. 1996. Movement and parametric variation in syntax. Irvine, CA: University of California, Irvine dissertation.

Takita, Kensuke. 2009. If Chinese is head-initial, Japanese cannot be. Journal of East Asian Linguistics 18. 41-61.

Tang, C-C. Jane. 1990. A note on the DP analysis of the Chinese noun phrase. Linguistics 28. 337-354.

Tang, C-C. Jane. 2005. Nouns or classifiers: A non-movement analysis of classifiers in Chinese. Language and Linguistics 6. 431-472.

Tang, Sze-Wing. 2006. Yueyu kuangshi xuci de jufa fenxi [A syntactic analysis of the discontinuous construction of function words in Cantonese]. Hanyu Xuebao [Chinese linguistics] 14. 16-23.

Tang, Sze-Wing. 2015. A generalized syntactic schema for utterance particles in Chinese. Lingua Sinica 1(3). 1-23. 
Tang, Sze-Wing, and Siu-Pong Cheng. 2014. Aspects of Cantonese grammar. In C.-T. James Huang, Y.-H. Audrey Li, and Andrew Simpson (eds.), The handbook of Chinese linguistics, 601-628. Malden, MA: Blackwell.

Tsai, Wei-tien Dylan. 2001. On subject specificity and theory of syntax-semantics interface. Journal of East Asian Linguistics 10. 129-168.

Tsai, Wei-Tien Dylan. 2015. A case of V2 in Chinese. Studies in Chinese Linguistics 36. 81-108.

Williams, Edwin. 2003. Representational theory. Cambridge, MA: MIT Press.

Zhang, Niina. 1999. Chinese de and the de construction. Syntaxis 2. 27-49.

Zhang, Niina. 2012. De and the functional expansion of classifiers. Language and Linguistics 13. 569-582.

Zimmermann, Malte. 2008. Discourse particles in the left periphery. In Benjamin Shaer, Philippa Cook, Werner Frey, and Claudia Maienborn (eds.). Dislocated elements in discourse: Syntactic, semantic, and pragmatic perspectives, 200231. London: Routledge.

Mailing address: Institute of Linguistics, Academia Sinica, 128, Section 2, Academia Road, Nangang, Taipei 115, Taiwan

Email: Iwwroger@gate.sinica.edu.tw

Received: December 6, 2016

Accepted: $\quad$ September 22, 2017 


\title{
再論後制後語序條件：從漢語中心語後置結構談起
}

\author{
廖偉聞 \\ 中央研究院語言學研究所
}

\section{提要}

本文討論關於 “後制後語序條件”（Final-over-Final Condition; FOFC）的問題。漢 語裡的句末助詞常被當作是反對 FOFC 的現象, 但事實上, 將句末助詞當作中心語 的句法分析仍缺乏強而有力的證據。另一方面, 漢語的名詞中心語能夠帶左邊補語 的現象 (Huang 2016 ) 不但違反了 FOFC, 同時對其提出更難以反駁的挑戰。然而, 我們認爲此種結構違反 FOFC 的理由肇因於漢語裡格位方向性的限制（Li 1990）, 同樣的衝突能夠在漢語及英語裡的複合詞結構裡看到。我們認爲這些現象透露出 FOFC 應該被當作是結構守恆原則（Williams 2003）的一個面向。也就是說爲了要 遵守某個語言特有的限制, 對共通原則最小程度的違反是可以被容忍的。

\section{關鍵詞}

後制後語序條件, 中心語後置結構, 表示論, 句末助詞, 漢語語法 